\title{
Laboreal
}

Volume $4 \mathrm{~N}^{\circ} 1$ | 2008

Ergologia, trabalho, desenvolvimentos

\section{O trabalho : componente esquecida no documento de estratégia de crescimento e de redução da pobreza nos Comores}

El trabajo : componente olvidada en el documento de estrategia de crecimiento y de reducción de la pobreza en los Comores

Le travail : Composante oubliee dans le document de strategie de croissance et de reduction de la pauvrete aux Comores

Work: A forgotten component in document that sets the strategy for growth and for poverty reduction in The Comoros

\section{Abdallah Nouroudine}

Tradutor: Liliana Cunha e Marianne Lacomblez

\section{(2) OpenEdition}

\section{Journals}

\section{Edição electrónica}

URL: http://journals.openedition.org/laboreal/11676

DOI: $10.4000 /$ laboreal. 11676

ISSN: 1646-5237

Editora

Universidade do Porto

\section{Refêrencia eletrónica}

Abdallah Nouroudine, « $\mathrm{O}$ trabalho : componente esquecida no documento de estratégia de crescimento e de redução da pobreza nos Comores », Laboreal [Online], Volume $4 \mathrm{~N}^{0} 1$ | 2008, posto online no dia 01 julho 2008, consultado o 20 outubro 2019. URL : http://journals.openedition.org/ laboreal/11676; DOI : 10.4000/laboreal.11676

\section{Este documento foi criado de forma automática no dia 20 outubro 2019.}

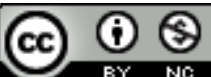

Laboreal está licenciado com uma Licença Creative Commons - Atribuição-NãoComercial 4.0 Internacional. 


\section{O trabalho : componente esquecida no documento de estratégia de crescimento e de redução da pobreza nos Comores}

El trabajo: componente olvidada en el documento de estrategia de crecimiento y de reducción de la pobreza en los Comores

Le travail : Composante oubliee dans le document de strategie de croissance et de reduction de la pauvrete aux Comores

Work: A forgotten component in document that sets the strategy for growth and for poverty reduction in The Comoros

\section{Abdallah Nouroudine}

Tradução : Liliana Cunha e Marianne Lacomblez

\section{NOTA DO EDITOR}

Manuscrito recebido em : Março/2008

Aceite após peritagem em : Maio/2008

1 Uma dupla degradação justifica plenamente uma reflexão sobre as condições necessárias para provocar uma dinâmica de desenvolvimento susceptível de incorporar ao mesmo tempo os meios da sua apropriação.

2 Primeiro, a precariedade das condições de vida de uma parte importante das populações que vive nos países do terceiro mundo. O relatório mundial sobre o desenvolvimento humano para o ano 2006 indica que existe uma distância considerável entre o país melhor classificado sobre o plano do Índice de Desenvolvimento Humano (Noruega com um IDH de 0,965) e o país menos bem classificado (Nigéria com um IDH 
de 0,311). Dos 177 países classificados segundo o IDH, 63 têm um IDH elevado, 83 têm um IDH médio e 31 têm um IDH fraco. Todos os países de IDH fraco (à excepção do Iémen e do Haiti) encontram-se situados em África. Relativamente aos Comores, classificados na 132éxima posição, eles são contados entre os países com IDH médio de 0,556 .

3 Segundo, não podemos hoje negligenciar a deterioração considerável da situação ecológica do planeta (poluição, desflorestação, aquecimento climático, erosão dos solos, etc.) devido à intervenção cega e irresponsável do homem sobre a natureza. Um tal contexto, torna oportuna uma reflexão sobre as condições, os meios e a gestão da realização das actividades humanas : por um lado, o trabalho que realiza o homem não chega ainda a produzir bens e serviços de maneira satisfatória para o conjunto das populações do planeta, e por outro lado, os impactos da intervenção do homem sobre o ambiente se não são sempre negativos, quando o são, são-no frequentemente de uma maneira catastrófica (cf. a deterioração da camada de ozono, o processo rápido de desflorestação, etc.).

4 A íntima convicção que anima esta reflexão consiste em considerar que uma abordagem dialéctica entre o "local" e "o global" ou entre o "singular" e o "universal" é necessária para enfrentar e resolver os problemas relativos à precariedade das condições de vida dos povos, por um lado, e à deterioração ecológica do planeta, por outro lado. Nesta ordem de ideias, dois problemas, dois elementos de resposta e uma dificuldade devem ser colocados de forma prévia à reflexão que será desenvolvida nas linhas seguintes. $O$ primeiro problema é o de saber : O que fazer para que o desenvolvimento seja perene ? Face a isto defendemos que o desenvolvimento só possa ser perene, se - e só se - for apropriado pelos povos e adaptado às realidades locais. Esta hipótese conduz de facto ao segundo problema, assim formulado : Como fazer para que o desenvolvimento seja apropriado pelos povos e adaptado às realidades locais? Respondemos a esta questão propondo que o desenvolvimento apenas possa ser apropriado pelos povos e adaptado às realidades locais se for concebido e conduzido a partir das actividades humanas, em geral, e do trabalho, em particular. Estas questões de partida vão funcionar como postulados no raciocínio que vamos construir em torno de uma dificuldade que ocupará o essencial do nosso propósito: Se é necessário passar pelo trabalho para conceber e realizar uma estratégia de desenvolvimento apropriado, então, como tratar o problema da ausência do trabalho nas abordagens clássicas do desenvolvimento ?

\section{0 trabalho é uma componente esquecida no desenvolvimento.}

5 A dificuldade essencial que põe a ausência do trabalho nas abordagens clássicas do desenvolvimento, é que o esquecimento inicial do trabalho acaba por se instalar de tal modo nos espíritos que depois já não se presta mais atenção ao que, de facto, é uma anomalia e que pesa bastante no fracasso dos programas de desenvolvimento. 0 primeiro esquecimento (é esquecida a integração do trabalho como um parâmetro importante do desenvolvimento) desdobra-se num outro esquecimento (é esquecido que o trabalho foi esquecido na abordagem do desenvolvimento). É assim que a ausência do trabalho na reflexão sobre o desenvolvimento se tornou uma prática "natural" que poucas pessoas pensam pôr em causa. Homens e mulheres de boa fé, a quem o modelo de desenvolvimento clássico não satisfaz, questionam a pouca 
importância atribuída ao "género", e aos "direitos do homem" ou ao "ambiente". É assim que nos Comores, a questão da revisão do Documento de Estratégia de Crescimento e Redução da Pobreza (DSRP) é estudada no âmbito de ateliers especialmente organizados para examinar as condições e as modalidades de integração das preocupações relativas ao "género" e aos "direitos do homem". Não se trata aqui de contestar a pertinência de tais revisões dado que é verdade que estas irão melhorar sensivelmente o documento inicial. Trata-se simplesmente de realçar a vontade de prosseguir o trabalho de melhoria do DSRP, por um lado, e de, por outro lado, assinalar o esquecimento do "trabalho", ausente neste documento, enquanto poderia também ser melhorado consideravelmente neste plano, pondo o trabalho no lugar que lhe convém numa estratégia de desenvolvimento digna deste nome.

6 A questão que temos o direito de levantar imediatamente é a de saber como tem sido possível esquecer o trabalho. Podemos tentar responder a partir de dois pontos de vista distintos que partem de uma noção comum, mas percebida diferentemente : o emprego. Primeiro, o ponto de vista de quem começa por fazer a constatação da ausência do trabalho, mas que acaba por esquecê-lo encontrando o "emprego" no DSRP. Este crê ingenuamente que se se fala de emprego, então necessariamente será colocada a questão do trabalho. $O$ outro ponto de vista é o de quem dá conta que o trabalho está efectivamente ausente, mas considera que só a questão do emprego merece ser colocada no DSRP. Para o primeiro ponto de vista (tendencialmente, o dos não-peritos), pode considerar-se que houve engano, pensando que o emprego conduz de maneira mecânica ao trabalho. Porque criar empregos investindo em sectores economicamente promissores não exige uma preocupação com a situação e as condições de trabalho. Aliás, a ligação suposta, de facto lógica, entre o emprego e o trabalho cruza-se permanentemente com relações de poder e conflitos de interesses que fazem das condições de trabalho não um efeito mecânico do emprego, mas um objecto de conquista social que passa por uma percepção clara da distinção que existe entre o trabalho e o emprego. Para o segundo ponto de vista, a apreciação depende do objectivo visado no desenvolvimento: só o emprego conta se for primordial melhorar a produtividade para favorecer o "crescimento económico" ou reduzir a taxa de desemprego - quaisquer que sejam as condições do trabalho real; mas se, como é legítimo considerar numa dinâmica de desenvolvimento, o objectivo for primeiro melhorar as condições de vida da população, então o trabalho deve ser mais do que um acessório ou uma simples escória do emprego. 0 trabalho deve estar no centro da abordagem do desenvolvimento. Dito de outro modo, a relação entre o emprego e o trabalho existe, mas a natureza, as condições e as modalidades desta relação têm de ser o produto de uma construção social, frequentemente conflituosa, onde nada é jogado de antemão, precisamente pelos interesses que aí estão em causa.

7 Se a melhoria das condições de trabalho é um aspecto importante da melhoria das condições de vida, como se pode razoavelmente pensá-lo, então a análise das consequências ou do sentido do esquecimento do trabalho nas estratégias de desenvolvimento clássicas deve ser levada ainda mais longe. Com efeito, podemos falar de desenvolvimento sem atribuir uma atenção ao trabalho? Em certas culturas, o trabalho ocupa um lugar central na construção das relações sociais. Mas noutras, o trabalho tem uma centralidade periférica, ou seja desempenha um papel importante para a produção orientada principalmente para a satisfação das necessidades de vida sem, no entanto, ter uma função determinante no plano simbólico e na construção das 
relações sociais. A sociedade comoriana situa-se tendencialmente nesta segunda categoria. Mas em todos os casos, é dificilmente concebível elaborar e pôr em prática uma estratégia de desenvolvimento com sucesso sem partir do trabalho e sem se apoiar sobre o trabalho. Porque a vocação primeira do trabalho é produzir para satisfazer necessidades de vida, e a finalidade primordial do desenvolvimento é melhorar as condições de vida. $O$ desenvolvimento nas situações de trabalho passa pela melhoria das condições de trabalho, e o desenvolvimento na vida humana multidimensional passa pela melhoria das condições de vida, não de um dado grupo social, mas do conjunto do colectivo de vida. Neste plano aderimos ao ponto de vista de Bartoli quando define o seu "novo paradigma do desenvolvimento", a saber :

(...) a procura exaustiva da cobertura das necessidades do estatuto humano da vida tal como se exprime e cresce nas comunidades históricas à medida da evolução das civilizações e das culturas, para todos e, prioritariamente, para os mais pobres, aos menores custos humanos, ecológicos, e instrumentais, englobando nesta última categoria os custos materiais e os custos financeiros (Bartoli, 1999, p. 17).

Esta abordagem do desenvolvimento repensado tem em conta a complexidade da vida humana colocando a exigência de associar o desenvolvimento com as necessidades, pondo como princípio o seu carácter universal (ele é "para todos"), plural (as necessidades são contextualizadas "em comunidades históricas") e multidimensional (ele é construído em torno de um "estatuto humano da vida" que é formado por várias dimensões). A articulação entre o trabalho e o desenvolvimento sugerida nesta reflexão é então um esforço para se apoiar sobre a melhoria das condições de trabalho (o que irá conduzir a melhorar a produção destinada à satisfação das necessidades de vida) para melhorar as condições de vida (o que supõe encontrar uma adequação entre a produção dos bens e dos serviços, por um lado, e as necessidades da vida, por outro lado). Numa tal óptica o esquecimento do trabalho parece ser a expressão do esquecimento do desenvolvimento considerado como um processo de melhoria das condições de vida da população. Poder-se-ia relativizar este propósito dizendo que o esquecimento do trabalho é a tradução de uma abordagem do desenvolvimento que perde a carruagem. Então, a boa fé dos iniciadores deste tipo de démarche não seria radicalmente colocada em causa, mas a questão de fundo do problema continuaria inalterado. Nestes diferentes casos, o "desenvolvimento" torna-se, apesar de tudo, uma vã palavra que encontra dificuldade a entrar na vida para transformá-la e torná-la melhor. Como o desenvolvimento acaba por perder a sua dinâmica transformadora para tornar-se unicamente uma palavra, um slogan, uma teoria... que se declina em "desenvolvimento humano", "desenvolvimento sustentável", "ecodesenvolvimento", "codesenvolvimento" à mercê da moda e da vontade das instituições do desenvolvimento sem conseguir mudar de maneira significativa a situação do "subdesenvolvimento", ou seja incapaz de criar uma situação que permitiria produzir bens e serviços para satisfazer as necessidades de vida? Será que o desejo de satisfazer "necessidades" retóricas e teóricas suplantou a vontade de compreender a vida para a transformar? Seja como for, um facto é inegável : paralelamente ao processo de desarticulação do trabalho e do desenvolvimento, a produção de novos discursos sobre a pobreza e a miséria provoca uma tomada de consciência internacional sobre a precariedade da vida de uma parte importante da humanidade, mas ao mesmo tempo faz esquecer "a competência a viver" investida na vida e, por vezes, na sobrevivência. Ora, esta abordagem do desenvolvimento pela deficiência - aliás, pela pobreza e pela miséria do 
povo - induz uma percepção do outro feita de uma compaixão idealmente honrosa, mas praticamente estéril. Esta orienta o olhar sobre a miséria do outro ao mesmo tempo que lança um véu sobre a sua grandeza, a sua "competência a viver", cuja fecundidade potencial tem de igual apenas a sua complexidade.

(...) Pela mediação do 'corpo-si', da linguagem, dos valores, entre o uso de si industrioso e os outros momentos da vida biológica, psíquica, política, cultural, múltiplas circulações em todos os sentidos cristalizam um núcleo comum e fluído de 'competência a viver' e as polaridades específicas de acordo com as características concretas onde os indivíduos têm de levá-lo a efeito (Schwartz, 2000, p. 483).

É graças a esta "competência a viver" que cada um sabe quanto a pobreza e a miséria não conduz fatalmente ao fim da vida. Para viver, ou mesmo sobreviver, apesar da pobreza e da miséria, cada homem e cada colectivo de vida cria e aperfeiçoa incessantemente a sua "competência a viver" aprendendo a negociar com os constrangimentos tanto do meio físico como do social e a superar as provas da vida pela sua experiência e sua consciência, ou seja pela referência a si, aos outros e ao mundo.

"As competências a viver" declinam-se "em competências para o trabalho" pela acção necessária do homem sobre o seu meio de vida. Ele faz assim uso de criatividade na actividade transformadora da natureza, cujos processos Maurice Godelier dizia que estavam na origem da cultura e da história.

O homem tem uma história porque transforma a natureza. E é mesmo da própria natureza do homem ter esta capacidade. A ideia é que de todas as forças que põem o homem em movimento e lhe fazem inventar novas formas de sociedade, a mais profunda é a sua capacidade de transformar as suas relações com a natureza transformando a própria natureza. E é esta capacidade que lhe dá os meios materiais para estabilizar este movimento, para o fixar para uma época mais ou menos longa numa nova forma de sociedade, de desenvolver e estender bem para além dos seus lugares de nascimento algumas das formas novas de vida social que inventou (Godelier, 1984, p. 10).

11 O estudo da "competência a viver" pode ser fecundo para compreender e melhorar as "condições de vida". Uma análise das competências nas situações de trabalho, não fraccionada e isolada da "competência a viver", mas em estreita relação com ela, favorece um melhor conhecimento e uma transformação mais eficaz das "condições de trabalho". Assim, compreender adequadamente e transformar eficazmente o que releva da actividade humana deveria passar por uma abordagem que a inscreve numa situação feita de vários níveis que integram contextos restritos, medianos e amplos (Nouroudine, 2003) que permitiria evitar mutilar e desnaturalizar ao mesmo tempo o homem e as actividades que o inscrevem num processo de formação pessoal e de socialização incessantemente renormalizado e reconfigurado, ainda que frequentemente de maneira imperceptível. 


\section{Programas de Ajustamento Estrutural às Estratégias de Crescimento e Redução da Pobreza}

Para reflectir sobre o problema da ausência do trabalho nas abordagens clássicas do desenvolvimento, propomos analisar as abordagens do desenvolvimento nos Programas de Ajustamento Estrutural (PAS) e nas Estratégias de Crescimento e de Redução da Pobreza (SCRP) observando o caso dos Comores. Este país é um arquipélago de quatro ilhas: Ngazidja (GrandeComore), Ndzuwani (Anjouan), Mwali (Mohéli) e Maoré (Mayotte) [1] situado no Oceano Índico, à entrada setentrional do Canal de Moçambique, entre o Noroeste de Madagáscar e a costa Sueste do continente africano. $72 \%$ da população comoriana vive em zona rural.

A economia comoriana é marcada por sete características importantes $\left[{ }^{2}\right]$ :

- Fracos desempenhos económicos : O Produto Nacional Bruto por habitante (PNB/hab.) é estimado a 450 \$ EUA em 2004. O PIB/hab. é de 1993 \$ EUA em 2005 [3] numa situação de crescimento médio que ascende a 2,2 \% entre 1999 e 2004. A taxa de inflação média é de 3,7 \% entre 1999 e 2004.

- Uma situação económica relativamente dual: Existe, por um lado, um sector agrícola principalmente de subsistência que representa cerca de 40 a $44 \%$ do PIB, em média, mas que ocupa contudo quase dois terços dos empregos, e, por outro lado, um sector terciário que representa cerca de 46 a $52 \%$ do PIB em média, mas que é dominado pelo comércio de importação. Observa-se, no entanto, um sector secundário relativamente marginal que representa cerca de 8 a $12 \%$ do PIB em média.

- Um importante défice da balança comercial : As exportações referem-se a três produtos da cultura agrícola de renda: baunilha, o cravo-da-índia e o Ylang-ylang. Em 2004, as exportações baixaram fortemente ( $42 \%$ ) devido à baixa cotação da baunilha. Isto teve um impacto negativo nas receitas orçamentais. Ao mesmo tempo, as importações, continuam a aumentar, o que agrava a situação de uma balança comercial deficitária.

- Uma dívida externa e interna importantes : A dívida externa dos Comores passou de 185 milhões de dólares EUA em 1990 a 264 milhões de dólares EUA em 2004. Esta representa 71 \% do PIB e $520 \%$ das exportações dos bens e serviços. Quanto à dívida interna, era considerada em 2004 de mais de 8 mil milhões de Francos Comorianos (FC).

- Uma forte dependência económica face ao exterior: A economia dos Comores depende fortemente, por um lado, da ajuda pública ao desenvolvimento que passou de 64 milhões de dólares em 1990 a 16 milhões em 2000 e, por outro lado, das transferências de fundos privados provenientes da diáspora comoriana que são estimadas em cerca de 20 mil milhões FC por ano.

- Um sector económico dito informal em plena expansão: As actividades económicas que compõem o sector dito informal são, nomeadamente, o pequeno comércio ambulante, a maçonaria, a carpintaria, a soldadura, a mecânica, a costura, etc. Essas actividades são consideradas informais por não serem oficialmente declaradas. É necessário contudo salientar que não são tão "informais" quanto se poderia crer à primeira vista, porque não são desprovidas nem de regras, nem de organização, nem de saberes, nem de valores. 0 sector económico "informal" é por conseguinte um sector onde são realizadas actividades regidas de acordo com regras, códigos, saberes, valores diferentes dos que estruturam a economia dita formal. Uma vez feita esta observação, a questão de fundo que deveria reter a 
atenção é a de saber qual orientação e qual tipo de estrutura económica favorece o desenvolvimento, ou seja a melhoria das condições de vida da população.

- Uma economia não mercantil tradicionalmente central : Para além das actividades do sector dito informal, encontra-se nos Comores actividades económicas submetidas não a uma lógica mercantil, mas a exigências sociais e simbólicas. Uma tal economia não mercantil existe nomeadamente através de trocas de bens e de serviços efectuados em actividades que participam na produção de relações sociais hierarquizadas e codificadas, nomeadamente no domínio matrimonial (formação das alianças, organização das relações de parentesco, ...), na estruturação das classes de idade [ [ ] (formação de classes de idade, modo de passagem nas classes de idade, repartição das actividades entre as classes de idade, ...) ou na mobilização da mão-de-obra [5] (oferta de uma mão-de-obra colectiva, codificação socioprofissional das actividades económicas, ...), etc. Trata-se de uma economia cujos fundamentos estão enraizados nos valores e na organização social tradicional comoriana. A sua sobrevivência não corresponde a um índice de arcaísmo, mas sim ao facto de ser percebida como uma resposta a uma necessidade social, simbólica e identitária.

14 A economia dita informal e a economia não mercantil representa uma parte não negligenciável (e no entanto frequentemente negligenciada ou mal estudada) da economia comoriana. Ignorando ou deformando a natureza, a organização e o funcionamento desta economia, as estratégias de desenvolvimento que são elaboradas nos Comores (ou para os Comores) passam ao lado de características importantes da sociedade comoriana e estão, por isso, pelo menos parcialmente, inadequadas e inadaptadas relativamente às realidades do país. Os Programas de Ajustamento Estrutural e as Estratégias de Crescimento e de Redução da Pobreza largamente apoiados por organizações da comunidade internacional - como o Fundo Monetário Internacional (FMI), o Banco Mundial ou a União Europeia - são a graus variáveis confrontados com este problema.

\section{Os Programas de Ajustamento Estrutural esqueceram o desenvolvimento}

No PAS os objectivos de melhoria das "condições de trabalho" e de melhoria das "condições de vida" não eram ausentes mas, até certo ponto, negados. Uma das medidas mais notórias do PAS consistiu em operar uma redução drástica das despesas públicas a fim de atingir o equilíbrio orçamental. A sua aplicação traduz-se nomeadamente pelo congelamento dos salários e redução dos efectivos da função pública. Esta passa, obviamente, por despedimentos e estímulos às saídas voluntárias sem que sejam instaurados dispositivos realmente operacionais de acompanhamento e reinserção socioprofissional das pessoas em causa. A consequência de tal medida foi favorecer o processo de empobrecimento da população. Muitas pessoas encontraram-se assim sem emprego, por conseguinte, sem fonte de rendimento regular. A outra medida importante do PAS proibiu ao Estado que subvencionasse os produtos e serviços de primeira necessidade como o arroz, o açúcar, o petróleo para as lâmpadas, etc. Trata-se de produtos de uso corrente que, em consequência, se tornam cada vez mais caros, enquanto que o poder de compra diminui e o desemprego aumenta. $\mathrm{O}$ avançar forçado para o empobrecimento é assim desencadeado e intensificado. $O$ efeito secundário de tais medidas, que vão acabar por se revelar num verdadeiro desastre, é o enfraquecimento considerável do papel do Estado ao ponto que a sua autoridade é cada 
vez mais colocada em causa. O ponto culminante da fragilização do Estado, provocada se não agravada pelo PAS, está na situação comoriana, na emergência do separatismo insular que ameaça a unidade nacional. E foi seguida pela adopção de uma constituição que comporta nela os germes de divisão e do empobrecimento contínuo. Está-se agora em condições de constatar que o PAS, em vez de ser um programa de desenvolvimento, foi um programa de subdesenvolvimento. As condições de trabalho e as condições de vida não foram, em nenhum momento, objecto de iniciativas visando a sua melhoria. Se os efectivos da função pública são pletóricos, não é necessário certamente mantê-los no Estado, mas quando se está numa abordagem de desenvolvimento (ou seja de melhoria das condições de vida), não se despede e não se conduz à saída, de maneira massiva, trabalhadores sem se assegurar de que vão poder voltar a trabalhar noutro lugar. O PAS foi um programa governado por uma lógica meramente económica e, mais precisamente, financeira. $O$ objectivo principal era ajustar a estrutura orçamental do Estado.

16 A desintegração social era o preço a pagar para atingir este objectivo. Millet e Toussaint observam que o (...) plano de ajustamento estrutural do FMI e do Banco Mundial, impostos a numerosos países endividados [...] que privilegiam o aspecto estatístico sobre o aspecto humano, tiveram, e têm ainda, consequências terríveis para as populações e as economias do Sul [...]. Os povos sofrem o martírio desde há 20 anos, a pobreza generaliza-se a grande velocidade e os critérios macroeconómicos privilegiados pelo FMI e o Banco Mundial não permitem em nada melhorar o bem-estar das populações mais pobres (Millet \& Toussaint, 2002, p. 92).

$\mathrm{O}$ insucesso do PAS nos Comores não é portanto um facto marginal. Em muitos países o PAS provocou motins : Zâmbia em 1986 ; Venezuela em 1989 ; Peru em 1991 ; Jordânia em 1989; Iémen em 1998; Costa de Marfim em 1999 ; Zimbabué em 2000 ; Argentina, Paraguai e Uruguai em 2001 e 2002 (za., p. 94-95).

\section{O Documento de Estratégia de Redução da Pobreza esquece o trabalho}

18 A análise crítica do Documento de Estratégia de Redução da Pobreza (DSRP) nos Comores é necessário, mas este exercício não é fácil porque as suas fraquezas (algumas das quais foram destacadas mais acima) são também a sua força quando são consideradas numa outra perspectiva. Com efeito, quando se inscreve o DSRP numa curta história das abordagens do desenvolvimento, é-se conduzido a reconhecer que a démarche não é a pior das que os países do terceiro mundo conheceram, no que diz respeito às "condições de trabalho" e às "condições de vida". Perante o que foi o PAS, é evidente que o DSRP é um plano que apresenta elementos positivos, mas que continua a ser ainda largamente perfectível. A ausência do trabalho é uma das lacunas desta estratégia de desenvolvimento. É tanto mais importante estar atento às insuficiências do DSRP que este constitui o plano de acção construído com base nas grandes orientações políticas de desenvolvimento expostas na Estratégia de Crescimento e Redução da Pobreza (SCRP). O DSRP é, por conseguinte, hoje o quadro de referência para o desenvolvimento nos Comores: "O SCRP constitui hoje o documento de referência da União dos Comores em matéria de desenvolvimento socioeconómico" (DSRP, 2005, p. 1). O plano de acção 2006/2009 elaborado com base no SCRP é composto por sete eixos estratégicos. Cada eixo é ele próprio constituído por vários programas 
prioritários de desenvolvimento. No conjunto, o plano de acção contém trinta e cinco programas prioritários de desenvolvimento, os quais são declinados em "intervenções concretas a levar a cabo para criar as condições de uma reactivação do crescimento e uma redução duradoura da pobreza" (DSRP, 2005), num total de 306 intervenções.

\section{O trabalho está ausente dos programas definidos nos eixos estratégicos de desenvolvimento}

19 Os eixos estratégicos e os programas prioritários de desenvolvimento apresentam-se do seguinte modo :

O primeiro eixo estratégico põe a exigência de criar condições de um desenvolvimento económico durável. Este eixo referese à reforma das finanças públicas, ao desenvolvimento e à reabilitação das infra-estruturas económicas e de comunicação e à reactivação do sector da energia. Este eixo é composto por três programas prioritários de desenvolvimento : 1) Melhorar o funcionamento do Estado e das finanças públicas; 2) Assegurar um aprovisionamento regular em energia a baixo custo ; 3 ) Desenvolver e reabilitar as infra-estruturas económicas e os serviços de comunicação básicos.

O segundo eixo estratégico visa relançar o sector privado pondo a ênfase sobre sectores promissores. Este eixo refere-se nomeadamente à promoção dos seguintes sectores : agricultura, pesca, criação, turismo, e os outros sectores privados, incluindo o sector financeiro. Este eixo é elaborado em torno de nove programas prioritários de desenvolvimento: 1) Apoiar a reestruturação e a consolidação do património imobiliário; 2) Apoiar a criação de um ambiente favorável ao desenvolvimento do sector agrícola; 3) Relançar a produção agrícola e agro-alimentar; 4) Criar um ambiente favorável ao desenvolvimento harmonioso do sector ; 5) Desenvolver a pesca ; 6) Melhorar o sistema de conservação, de transformação e de comercialização dos produtos haliêuticos (pesca marítima) ; 7) Proteger o gado contra as doenças infecciosas exóticas e intensificar as fileiras de produções animais ; 8) Apoiar o desenvolvimento turístico ; 9) Promover o sector privado.

O terceiro eixo estratégico consiste em reforçar a governação e a justiça. Este eixo visa consolidar as instituições nacionais, melhorar a governação e a eficácia das instituições constitucionais e garantir um acesso e uma justiça equitativa para todos os cidadãos. É formado por quatro programas prioritários de desenvolvimento: 1) Reforçar a reconciliação nacional e pôr em prática as instituições constitucionais ; 2) Promover a luta contra a corrupção e melhorar a transparência na gestão dos assuntos públicos ; 3 ) Tornar efectiva e eficaz a descentralização ; 4) Reforçar as capacidades e a credibilidade da justiça.

O quarto eixo estratégico visa melhorar o estado sanitário da população. 0 governo concentrará os seus esforços sobre a luta contra as doenças prioritárias, a melhoria da saúde materna, a prevenção em matéria de infecções sexualmente transmissíveis e de VIH/SIDA, e a melhoria da gestão do sistema de saúde. Este eixo é composto por quatro programas de desenvolvimento prioritário : 1) Lutar contra as doenças prioritárias ; 2) Assegurar um desenvolvimento integrado da saúde reprodutiva/planeamento familiar (SR/PF) nas formações sanitárias periféricas ; 3) Lutar contra o VIH/SIDA e as infecções sexualmente transmissíveis ; 4) Reforçar a eficácia e a eficiência do sistema de saúde. 
O quinto eixo estratégico tem por objecto promover a educação e a formação profissional para melhorar o capital humano. 0 eixo estratégico 5 visa consolidar o desenvolvimento do sector da educação e da formação profissional de maneira a produzir uma sociedade educada, capaz de aproveitar as oportunidades económicas e socialmente responsável. É elaborado em torno de seis programas prioritários de desenvolvimento : 1) Melhorar o acesso das crianças entre 3 e 5 anos a uma educação adaptada ; 2) Melhorar a qualidade da educação básica e o desenvolvimento do ensino secundário ; 3) Promover e diversificar o ensino técnico e a formação profissional ; 4) Reforçar o ensino superior e a investigação ; 5) Favorecer a alfabetização e a promoção dos jovens e dos adultos; 6) Reforçar as capacidades institucionais de gestão e planificação da educação.

O sexto eixo estratégico tem por objectivo promover um ambiente são e garantir a durabilidade do desenvolvimento. Este eixo reveste-se de um interesse particular porque as questões ambientais afectam todas as actividades económicas nos Comores e têm uma incidência directa na qualidade de vida e nas condições sanitárias da população. Este eixo é constituído por seis programas prioritários de desenvolvimento : 1) Assegurar a conservação dos recursos naturais e o desenvolvimento das actividades estimuladas pela riqueza da fauna e da flora dos Comores ; 2) Manter um solo fértil, restaurar os solos degradados e gerir duravelmente os recursos florestais ; 3) Colocar em prática um mecanismo de financiamento duradouro para o ambiente ; 4) Pôr em prática uma política de gestão integrada das zonas costeiras; 5) Sanear as zonas urbanas ; 6) Aumentar a taxa de cobertura de água, e assegurar a preservação e a gestão sustentável deste recurso.

O sétimo eixo estratégico visa reforçar a segurança e a luta contra o terrorismo. Este eixo visa assegurar a segurança dos bens e das pessoas e lutar contra o terrorismo. É composto por três programas prioritários de desenvolvimento: 1) Lutar contra o terrorismo e a criminalidade transnacional ; 2) Reforçar a segurança dos bens e das pessoas ; 3) Melhorar a segurança civil.

Onde está o trabalho no DSRP ? Pode dar-se conta que nestes eixos estratégicos e nestes programas prioritários de desenvolvimento o trabalho é certamente uma componente esquecida. As questões do trabalho, em geral, e da melhoria das condições de trabalho, em particular, são completamente ignoradas.

\section{0 trabalho está ausente das "intervenções" abrangidas pelos programas prioritários de desenvolvimento}

Três tipos de dificuldades devem salientar-se relativamente à ausência do trabalho no DSRP :

Primeira dificuldade : No DSRP, fala-se muito de emprego, ora este pode mascarar, não o trabalho, mas a ausência do trabalho. É o caso por exemplo numa "das intervenções" prevista no eixo 5, programa 3 : "Criação de um observatório do emprego e classificação nacional das profissões". "Um Observatório do Emprego" não observa automaticamente também o trabalho. Se o trabalho tivesse sido realmente uma preocupação no DSRP, podia eventualmente ter sido referido um "Observatório do Trabalho e do Emprego". 
30 Segunda dificuldade : Em vários programas, podemos vislumbrar a sombra do trabalho sem que, no entanto, nada na orientação política e metodológica dê matéria a pensar que o trabalho ou a actividade vai realmente emergir e estar no cerne da démarche de aplicação das "intervenções" enumeradas nos programas deste eixo. É o caso do sexto eixo no qual se encontra definido um certo número de "intervenções" a efectuar, entre as quais várias contêm potencialmente o trabalho. Alguns exemplos de "intervenções" deste eixo permitem dar conta desta dificuldade :

- "Aplicação das técnicas alternativas". Entre as dificuldades específicas a estas "intervenções" podemos assinalar a questão da escolha das "técnicas alternativas". O trabalho real (a actividade) será tido em conta na escolha das "técnicas alternativas" ? A démarche de "aplicação das técnicas alternativas" permitirá ter em conta os parâmetros específicos da situação de trabalho?

- "Integração da exploração florestal e de arborização às actividades culturais". A "integração" de "arborização" no trabalho agrícola está longe de ser uma questão simples. Esta "intervenção" coloca o problema complexo da "inovação" e da apropriação de uma nova "técnica" de trabalho. As experiências realizadas nos Comores relativas à arborização conheceram destinos diversos. Se os camponeses da região de Nyumakele a Ndzuwani (Anjouan) bem se apropriaram desta técnica, não é o caso das outras regiões onde a introdução da arborização foi tentada. Isto indica que não há incidência mecânica entre a "introdução" de uma técnica e a "integração" (a apropriação) desta. O destino reservado ao trabalho real (a actividade) no processo de introdução acaba por determinar o sentido do seu resultado : apropriação ou rejeição. O mesmo tipo de problema é susceptível de se colocar para as intervenções tais como a "adopção de práticas culturais adaptadas às necessidades e condições ecológicas locais" ou à "restauração e protecção das massivas florestas naturais".

Terceira dificuldade: No DSRP, fala-se frequentemente de sectores de actividades económicas promissores, mas a actividade de trabalho e as condições de trabalho nunca são abordadas. Das 306 intervenções previstas nos trinta e cinco programas prioritários de desenvolvimento nenhuma é orientada para a melhoria das condições de trabalho. Poder-se-ia esperar que o segundo e o sexto eixos fossem a ocasião de colocar a exigência de ter em conta o trabalho, em geral, e as condições de trabalho, em particular. Ora nestes eixos, e particularmente no segundo eixo, são destacados os sectores económicos potencialmente promissores a saber a agricultura, a pesca, a criação, o turismo e os outros sectores privados sem que se saiba como a questão do trabalho real vai ser colocada e abordada. 0 quadro abaixo apresenta a integralidade das "intervenções" desenvolvidas nos programas do segundo eixo : "Relançar o sector privado pondo a ênfase sobre os sectores promissores".

\begin{tabular}{|l|l|l|}
\hline \multicolumn{2}{|l|}{ Progr. } & Intervençães \\
\hline 1 & 1. & Actualização do estudo básico sobre os direitos de propriedades imobiliárias \\
\hline 2. & $\begin{array}{l}\text { Adopção de uma legislação do imobiliário que comporte a obrigação de registo de todas as } \\
\text { terras agrícolas }\end{array}$ \\
\hline 3. & Operacionalização dos serviços centrais e insulares de cadastro \\
\hline 4. & $\begin{array}{l}\text { Identificação dos sítios vulneráveis à actividade agrícola e instauração de comités de } \\
\text { ordenamento }\end{array}$ \\
\hline 5. & Apoio às actividades de ordenamento e protecção dos sítios vulneráveis \\
\hline
\end{tabular}




\begin{tabular}{|c|c|c|}
\hline 2 & 6. & $\begin{array}{l}\text { Criação de uma câmara da agricultura para acompanhar a profissionalização das } \\
\text { organizações dos produtores }\end{array}$ \\
\hline \multicolumn{2}{|c|}{7.} & Reforçar as capacidades das organizações profissionais do sector \\
\hline \multicolumn{2}{|c|}{8.} & Reforço das capacidades das administrações da agricultura \\
\hline \multicolumn{2}{|c|}{9.} & Reabilitação física dos centros de enquadramento agrícolas e lançamento das actividades \\
\hline \multicolumn{2}{|c|}{10.} & Redefinição da missão dos centros de enquadramento agrícolas \\
\hline 3 & 11. & Reabilitação das infra-estruturas de apoio à produção alimentícia e hortícola \\
\hline \multicolumn{2}{|c|}{12.} & $\begin{array}{l}\text { Promoção e desenvolvimento de pequenas unidades de transformação e conservação dos } \\
\text { produtos agrícolas e alimentares }\end{array}$ \\
\hline \multicolumn{2}{|c|}{13.} & $\begin{array}{l}\text { Introdução de novos produtos alimentícios de alto rendimento e adaptados ao gosto dos } \\
\text { consumidores locais }\end{array}$ \\
\hline \multicolumn{2}{|c|}{14.} & Apoio aos produtores de baunilha para melhorar a qualidade da produção \\
\hline \multicolumn{2}{|c|}{15.} & Reabilitação das plantações de ylang-ylang e melhoria das técnicas de destilação \\
\hline \multicolumn{2}{|c|}{16.} & Reforçar a mercantilização do cravo-da-índia \\
\hline \multicolumn{2}{|c|}{17.} & $\begin{array}{l}\text { Estudo de viabilidade técnica e de viabilidade financeira de novas culturas de renda } \\
\text { (pimenta verde, combaya, canela, gengibre, baga rosa, etc.) }\end{array}$ \\
\hline \multicolumn{2}{|c|}{18.} & Instaurar parcelas de experimentação das novas culturas potenciais \\
\hline \multicolumn{2}{|c|}{19.} & $\begin{array}{l}\text { Apoio à organização e à mercantilização dos produtos das novas fileiras de rendas } \\
\text { promissoras }\end{array}$ \\
\hline 4 & 20. & Reforçar as capacidades das organizações profissionais do sector \\
\hline \multicolumn{2}{|c|}{21.} & Reforço das capacidades das administrações de pesca \\
\hline 5 & 22. & Tornar disponíveis os motores das pequenas embarcações a preços acessíveis \\
\hline \multicolumn{2}{|c|}{23.} & Multiplicação dos DCP (dispositivos de concentração de peixe) \\
\hline \multicolumn{2}{|c|}{24.} & $\begin{array}{l}\text { Reforçar as capacidades para a nova renegociação/negociação de acordos de pesca para } \\
\text { permitir maiores ganhos nos Comores }\end{array}$ \\
\hline \multicolumn{2}{|c|}{24.} & Apoio à criação de uma frota semi-industrial \\
\hline 6 & 25. & $\begin{array}{l}\text { Instalação e reabilitação dos equipamentos colectivos de conservação e de comercialização } \\
\text { nas três ilhas }\end{array}$ \\
\hline \multicolumn{2}{|c|}{26.} & Instauração de infra-estruturas de transbordo \\
\hline \multicolumn{2}{|c|}{27.} & Instauração de uma autoridade de controlo sanitário reconhecida a nível internacional \\
\hline & 28. & Lutar contra as doenças transmitidas pela carraça (Babesiosa, Cowdriose, théilériose) \\
\hline 29 & & Lutar contra a peste da manqueira \\
\hline 30 & & $\begin{array}{l}\text { Reforçar e aplicar a legislação de controlo zoo-sanitário às fronteiras para impedir } \\
\text { qualquer nova introdução das doenças infecciosas }\end{array}$ \\
\hline 31 & & $\begin{array}{l}\text { Criar um Centro Nacional de Compra e de Abastecimento dos Produtos Veterinários e a } \\
\text { abertura das clínicas/depósitos veterinários ao nível de cada ilha }\end{array}$ \\
\hline 32 & & Apoio à produção avícola \\
\hline 33 & & Intensificação da produção avícola \\
\hline
\end{tabular}




\begin{tabular}{|c|c|}
\hline 34. & Promoção da produção de carne das criações caprinas \\
\hline 35. & $\begin{array}{l}\text { Promoção das criações leiteiras das raças bovinas puras em quintas cooperativas ou } \\
\text { individuais privadas }\end{array}$ \\
\hline 36. & $\begin{array}{l}\text { Instauração de quintas-piloto de experimentação e de abastecimento em sementes animais } \\
\text { e progenitores de raça pura ou métis }\end{array}$ \\
\hline 837. & Instauração do local e operacionalização das direcções do turismo das ilhas e da união \\
\hline 38. & Criação de um posto de turismo nas três ilhas \\
\hline 39. & Criação do Posto Nacional do Turismo (ONT) \\
\hline 40. & Criação de Sítios WEB \\
\hline 41. & Participações nas feiras internacionais \\
\hline 42. & Aquisição de uma documentação turística \\
\hline 43. & Criação de um ponto de apoio na Europa \\
\hline 44. & Reabilitação dos hotéis e albergues existentes \\
\hline 45. & Criação de estabelecimentos hoteleiros \\
\hline 46. & Criação dos abrigos de ecoturismo \\
\hline 47. & Centro de formação nos ofícios da hotelaria e da restauração \\
\hline 48. & Formação profissionalizante de guias intérpretes turísticos \\
\hline 49. & Formação permanente dos actores (público-privados) \\
\hline 50. & Reabilitação dos monumentos e dos sítios existentes \\
\hline 51. & Valorização do vulcão Karthala \\
\hline 52. & Ordenamento dos caminhos de passeios \\
\hline 53. & Apoio ao parque arinho de Mohéli (PMM) \\
\hline 54. & Incitação ao agro-turismo \\
\hline 55. & Parque do coelacanthe \\
\hline 56. & Actividades náuticas em Chindini \\
\hline 57. & Promoção de outros pólos de atracção \\
\hline 58. & Incitação à criação de sítios turísticos \\
\hline 59. & $\begin{array}{l}\text { Apoio ao desenvolvimento e promoção do CNAC (centro nacional do artesanato dos } \\
\text { Comores) }\end{array}$ \\
\hline 60. & Valorização e colocação em cena do folclore nacional \\
\hline 961. & $\begin{array}{l}\text { Reforço das capacidades institucionais dos ministérios responsáveis pela promoção do } \\
\text { sector privado (União e ilhas) }\end{array}$ \\
\hline 62. & Eliminação das barreiras comerciais formais e informais entre as ilhas \\
\hline 63. & Código de investimento e outras medidas de incentivo ao investimento adoptado \\
\hline 64. & Adopção, promulgação e operacionalização do código dos mercados públicos \\
\hline 65. & $\begin{array}{l}\text { Vulgarização e aplicação do plano contabilístico da OHADA (organização para a } \\
\text { harmonização na África do direito comercial) nas empresas }\end{array}$ \\
\hline
\end{tabular}




\begin{tabular}{|l|l|}
\hline 66. & Reforço dos mecanismos de conciliação e de arbitragem comercial \\
\hline 67. & Criação de um Centro Comoriano do Comércio externo \\
\hline 68. & Apoio ao desenvolvimento de serviços-conselhos \\
\hline 69. & $\begin{array}{l}\text { Reforço das Câmaras de Comércio, de Indústria e de Artesanato (CCIA) das ilhas e da } \\
\text { Câmara de Comércio, de Indústria e de Artesanato (UCCIA) da União }\end{array}$ \\
\hline 70. & Reforço das capacidades em matéria de gestão dos serviços financeiros \\
\hline 71. & $\begin{array}{l}\text { Definição e colocação em prática de uma política de acompanhamento e controlo das IFD } \\
\text { (instituições financeiras descentralizadas - microcréditos) pelas autoridades de tutelas } \\
\text { (Banco Central dos Comores, Ministério das finanças) }\end{array}$ \\
\hline 72. & Favorecer a implantação de novas instituições financeiras formais \\
\hline 73. & $\begin{array}{l}\text { Incentivar a inovação e o desenvolvimento de novos produtos financeiros adaptados às } \\
\text { necessidades do sector privado e das populações }\end{array}$ \\
\hline 74. & Apoio à criação de um mecanismo obrigatório de seguro da poupança nos IFD \\
\hline 75. & $\begin{array}{l}\text { Apoio à criação de um sistema de garantias que permita reduzir os riscos dos créditos } \\
\text { produtivos }\end{array}$ \\
\hline
\end{tabular}

A ausência de um programa ou de intervenções sobre a segurança e a saúde no trabalho dos pescadores é uma vez mais reveladora do esquecimento do trabalho na abordagem do desenvolvimento no DSRP. Se o ponto de vista do trabalho tivesse estado presente neste documento, teria sido difícil não tratar um problema tão importante sabendo que regularmente pescadores desaparecem no mar trabalhando em condições muito difíceis : águas muito agitadas, meios de segurança quase nulos, barcos que não estão sempre adaptados à realidade física do meio de trabalho, etc.

No entanto, convém notar que existem várias "intervenções" neste eixo que poderiam prestar-se a uma abordagem pelo trabalho. É o caso das "intervenções" 6, 7, 12, 14, 15, $18,20,23,25,27,33,34,37,48,49,50,55,59,60,61$. A indicação de alguns destes exemplos tem por objectivo mostrar que o DSRP contém programas e "intervenções" que poderiam constituir uma ocasião para considerar o trabalho segundo três modalidades : primeiro, pondo em relevo a dimensão trabalho dos programas e das "intervenções"; depois, pondo a actividade humana no centro da démarche de aplicação do DSRP ; e por último, integrando um eixo sobre a melhoria das condições de trabalho no qual seriam contempladas "intervenções" concretas em torno da saúde no trabalho, da formação contínua, da protecção social, da remuneração do trabalho, do reconhecimento do trabalho, da inovação tecnológica, da legislação do trabalho, etc.

\section{Conclusão : pôr a actividade no cerne do trabalho e o homem no centro do desenvolvimento para poder pensá-los e vivê-los conjuntamente}

34 A originalidade destes temas de intervenção pode revelar-se, e ao mesmo tempo servir objectivos de desenvolvimento, apenas se o trabalho for considerado na sua complexidade. Referindo a distinção ergológica entre as "normas antecedentes" e a "renormalização", podemos razoavelmente considerar que a dimensão prescritiva ou 
mesmo normativa dos "eixos estratégicos", dos "programas prioritários" e das "intervenções" deverá dar lugar a um processo de renormalização pelos actores que vão encarregar-se da sua realização efectiva para traduzir as orientações e os objectivos de desenvolvimento em actividades de desenvolvimento de modo a que a vida real das populações possa mudar no sentido de uma melhoria. Mas se, no plano da renormalização, o trabalho real não pode ser apresentado em termos de prescrição dito de outro modo se não pode ser totalmente antecipado portanto programado então o problema que é aqui colocado não é o de não encontrar o trabalho real como tal no DSRP, mas antes de não encontrar grandes objectivos relativos ao trabalho, nomeadamente no que concerne à melhoria das condições de trabalho. Determinada como prioridade, esta induziria de facto uma abordagem das "intervenções" que não poderia descurar a consideração dos constrangimentos, das possibilidades e dos recursos das situações reais de vida, em geral, e das situações reais de trabalho, em particular. Uma tal reconsideração epistemológica e ética leva a pôr a actividade no cerne do trabalho e o homem no centro do desenvolvimento, a fim de que as populações em causa possam pensá-los e vivê-los conjuntamente.

\section{BIBLIOGRAFIA}

Bartoli, H. (1999). Repenser le développement. Paris : UNESCO. Godelier, M. (1984). L'Idéel et le matériel. Paris : Fayard.

Millet, D. et Toussaint, E. (2002). 50 questions, 50 réponses sur la dette, le FMI et la Banque mondiale. Paris : Syllepse.

Ministère du Plan, de l'Aménagement du territoire, de l'Energie et de l'Urbanisme. (2005). Document de Stratégie de Croissance et de Réduction de la Pauvreté. Moroni : Commissariat Général au Plan.

Nouroudine, A. (2003). Travail et mobilisation de la main-d'œuvre : éléments d'analyse épistémologique. in Sandrine Michel et Xavier Oudin (orgs.), La mobilisation de la main-d'œuvre (pp. 175-190). Paris : L’Harmattant.

PNUD. (2006). Rapport mondial sur le développement humain 2006. Au-delà de la pénurie : Pouvoir, pauvreté et crise mondiale de l'eau. Paris : Economica.

Schwartz, Y. (2000). Les ingrédients de la compétence : un exercice nécessaire pour une question insoluble. In Le paradigme ergologique ou un métier de philosophe (pp. 479-503). Toulouse : Octares Editions.

Union des Comores. (2005). Objectifs du Millénaire pour le Développement. Rapport National 2005. Moroni. Union des Comores et Nations Unies. 


\section{NOTAS}

1. Trinta e três anos após a proclamação da independência dos Comores, a ilha de Maoré encontra-se ainda sob administração francesa.

2. Salvo indicação contrária, as cinco primeiras características e os dados referidos são aqueles que foram apresentados no Relatório Nacional 2005 dos "Objectifs du Millénaire pour le Développement" (OMD), publicado pela União dos Comores e as Nações Unidas.

3. Fonte: Relatório mundial sobre o desenvolvimento humano 2006. (Cf. referências completas na bibliografia)

4. Cf. a este propósito, a descrição e análise feita por Sultan Chouzour em: Chouzour, S. (1994). Le pouvoir de l'Honneur. Tradition et contestation en Grande-Comore, L'Harmattan, Paris.

5. Cf. relativamente à mobilização da mão-de-obra na sociedade tradicional comoriana, o nosso artigo cujas referências são apresentadas na bibliografia (Nouroudine, 2003).

\section{RESUMOS}

As abordagens clássicas do desenvolvimento negligenciam o trabalho, em geral, e as condições de trabalho, em particular. Desde os Programas de Ajustamento Estrutural às Estratégias de Crescimento e Redução da Pobreza, observa-se uma integração relativa da pluralidade das dimensões da vida. No entanto, o trabalho nem sempre é tido realmente em conta. Isto compromete as possibilidades de transformar as estratégias e os objectivos de desenvolvimento em actividades e trabalho de desenvolvimento, de modo a transformar ao mesmo tempo as condições de trabalho e as condições de vida da população. Uma melhor consideração do trabalho e das actividades humanas favoreceria a apropriação, pelas populações locais, dos processos de transformação próprios ao desenvolvimento.

Los planteamientos clásicos del desarrollo tratan con negligencia el trabajo, en general, y las condiciones de trabajo, en particular. Desde los Programas de Ajuste Estructural a las Estrategias de Crecimiento y Reducción de la Pobreza, se observa una integración relativa de la pluralidad de las dimensiones de la vida. Sin embargo, el trabajo no siempre se le tiene realmente en cuenta. Esto compromete las posibilidades de transformar las estrategias y los objetivos de desarrollo en actividades y trabajo de desarrollo, de forma a transformar al mismo tiempo las condiciones de trabajo y las condiciones de vida de la población. Una mejor consideración del trabajo y de las actividades humanas favorecería la apropiación, por las poblaciones locales, de los procesos de transformación en el meollo del desarrollo.

Les approches classiques du développement font l'impasse sur le travail, en général, et sur les conditions de travail, en particulier. Des Programmes d'Ajustement Structurel aux Stratégies de Croissance et de Réduction de la Pauvreté, on observe une intégration relative de la pluralité des dimensions de la vie. Toutefois, le travail n'est toujours pas réellement pris en compte. Cela compromet les possibilités de transformer les stratégies et les objectifs de développement en activités et travail de développement de nature à transformer à la fois les conditions de travail et les conditions de vie de la population. Une meilleure prise en compte du travail et des activités humaines serait de nature à favoriser l'appropriation des processus de transformation au cœur du développement par les populations locales. 
Classical development approaches neglect work, in general, and its conditions in particular. From the Structural Adjustment Programs to the Strategies for Growth and for Poverty Reduction, we observe a relative integration of the plurality of life dimensions. Nevertheless, work is not always really considered. This compromises the possibilities of transforming strategies and goals for development in activities and work for development, in order to simultaneously transform people's work conditions and life conditions. A better consideration of work and of human activities would favour the appropriation by local populations of the transformation processes inherent to development

\section{ÍNDICE}

Mots-clés: activité, développement, emploi, pauvreté, travail

Palabras claves: actividad, desarrollo, empleo, pobreza, trabajo

Keywords: activity, development, employment, poverty, work

Palavras-chave: actividade, desenvolvimento, emprego, pobreza, trabalho

\section{AUTORES}

\section{ABDALLAH NOUROUDINE}

Université des Comores, B.P. 18, Moroni COMORES

abdanouroudine@yahoo.fr 